\title{
The Economic Impacts of Renewal Energy on Local Economies: The Case of Solar Energy in Japan
}

\author{
Hitoshi Hayami ${ }^{1}$ and Masao Nakamura ${ }^{1,2,{ }^{*}}$ \\ ${ }^{1}$ Faculty of Business and Commerce, Keio University, Tokyo, 108-8345, Japan \\ ${ }^{2}$ Sauder School of Business, University of British Columbia, Vancouver, V6T 1Z2, Canada
}

\begin{abstract}
Various alternative renewable energy sources have been proposed and implemented. These energy sources, which generally do not rely on fossil fuel, are distinguished from the traditional large scale energy projects in a number of ways.

On the other hand, the circumstances surrounding renewable energy sources currently under use are characterized by their small size and scale and their economic impacts are generally local. For example, wind mills based electric power generation uses locally available wind currents and geothermal power generation uses locally available geothermal heat sources. Similarly, solar power generation uses solar power available in the local regions. These imply that the economic impacts of most renewable energy sources currently in use are local.

We estimate our model using cross-sectional data of regional economies measured at the prefecture level in Japan. This will allow us to estimate the impacts of certain government policy variables at the regional level as well. One hypothesis we consider in this paper is that while solar power is still negligible in terms of its impact on Japan's national economy, it has some economic impacts on the economies of the regions where they are located.
\end{abstract}

Keywords: Local renewable energy generation, regional economies, regional income and employment.

\section{INTRODUCTION}

Various alternative renewable energy sources have been proposed and implemented. These energy sources, which generally do not rely on fossil fuel, are distinguished from the traditional large scale energy projects in a number of ways. For example, traditional large-scale nuclear power, coal burning and oil burning power generation methods typically use massive amounts of energy sources like uranium, coal and oil which are transported from far away (though locally available resources are also used). Their economic impacts generally extend to beyond the localities where they are located. Large scale hydro power plants are exceptional in that they are large in scale and also nonfossil fuel based.

On the other hand, the circumstances surrounding renewable energy sources currently under use are characterized by their small size and scale and their economic impacts are generally local. For example, wind mills based electric power generation uses locally available wind currents and geothermal power generation uses locally available geothermal heat sources. Similarly, solar power generation uses solar power available in the local regions. These imply that the economic impacts of most renewable energy sources currently in use are local.

*Address correspondence to this author at the Sauder School of Business, University of British Columbia, Vancouver, V6T 1Z2, Canada; Tel: (604) 8228434; Fax: (604) 822-8477; E-mail: masao.nakamura@sauder.ubc.com
Many studies in the literature exist that consider the role of the energy sector in Japan's national economy. In contrast, this paper focuses on an exploratory analysis of economic implications of the renewable energy sources, particularly solar power, for the regional economies. We analyze empirically how dependent variables such as regional income and employment are affected by investments in renewable energy in the region. We estimate our model using cross-sectional data of regional economies measured at the prefecture level in Japan. This will allow us to estimate the impacts of certain government policy variables at the regional level as well. One hypothesis we consider in this paper is that while solar power is still negligible in terms of its impact on Japan's national economy, it has some economic impacts on the economies of the regions where they are located. ${ }^{1}$

${ }^{1}$ In this paper we focus our attention on the economic impacts of solar power investment. The reasons for this are twofold: (1) power generation from other renewal sources is much smaller compared to solar power (e.g. $203595 \mathrm{~kW}$ for solar power vs. $1759 \mathrm{~kW}$ for biofuel) and their observations contain many zeros (see Table 1), making measurement of the economic impacts of power from these non-solar sources difficult; and (2) woody biomass constitutes $8 \%$ of the total biomass material, of which $80 \%$ are waste and construction wastes, and rest of which are methane gas and agricultural wastes. All of non-woody biomass is waste from garbage collected and gets delivered by existing channels. Also half of woody biomass (55\%, 5,510 kilo ton) is imported material (palm kernel shell, imported chips and pellets). Woody biomass is considered to be non-sustainable in Japan because of its domestic supply shortage and also the higher (3 times per weight) cost of domestic supply than the cost of the imported. And sales distribution of biomass is not necessarily limited to local areas [1] 


\section{A BASIC FRAMEWORK FOR EMPIRICAL ANALYSIS: MODEL AND DATA}

We first present our basic framework for or crosssectional analysis of the implications of renewal energy use for the local Japanese economies. The basic unit of observation is prefecture or equivalent, ${ }^{2}$ for which we have data. The descriptive statistics for the basic variables we use are presented in Table 1 . The economic variables we explain here are per capita income (per year, in one thousand yen), employed earnings per employed person (per year, in thousand yen), the number of workers and the number of employed workers.

The primary explanatory variables of our interest are the capacity in $\mathrm{kW}$ of each of renewable energy generation: biofuel, geothermal, hydro, wind and solar (photo voltaic (PV)). The capacity of these renewable energy sources is accurately measured by the amounts of cumulative investment in each source (Table 1). However, the amount of actually generated electric power depends not only on the generator capacity but also the amounts of sunshine for each community. For this reason, in our study we use PVSUN (=PV capacity $x$ hours of annual sunshine in kWh) instead of PV capacity. In addition, we use two additional control variables: population density (persons $/ \mathrm{km} 2$ ) and Tokyo dummy ( $=1$ if the observation is Tokyo, $=0$ otherwise). Population density is included since population density matters in the investment behavior at the prefecture level. Tokyo dummy was also included to control for the large size and extraordinary economic characteristics of the Tokyo region. ${ }^{3}$ Most of our variables were measured in 2013-2014. But variables on the capacity of electric power generation for various renewable energy sources were collected over the period 20122014.

In Japan, as in other advanced economies, the relative numbers of employed non-regular workers of various types have increased compared to the number of long-term regular employed workers. These nonregular employed workers include those in the categories of temporary, part-time, contract, sent-in and other employment. In our data the employed workers include all types of employed workers. This is unfortunate because many of the current policy issues

\footnotetext{
${ }^{2}$ Japan has 47 prefectures, the Tokyo capital area (Tokyo-to) and two special prefectures, Osaka-hu and Kyoto-hu.

${ }^{3}$ For this reason Tokyo was eliminated in some of our regressions below. Population density variable was not statistically significant.
}

are with respect to differential impacts of macro events on the different types of employed workers. Table 1 shows that employed workers constitute a large fraction of Japanese all workers. Our variable Workers here includes self-employed workers.

Our income variables are per capita income and employment income per employed person. Employment income generally exceeds per capita income by a large amount as expected. Population Density variable shows the highly skewed distribution of the Japanese population across the country. Population density ranges from the highest 6314.6 to the lowest 65.1 people per squared kilometer across prefectures.

Of all renewable sources of electric power we consider in this study solar power (PV) generates by far the largest electric power. Solar power is followed by Wind, Biofuel, Hydro and Geothermal power. ${ }^{4}$ The basic reasons for this are that: first, Japan has abundant sunshine across the country in general and many regions have land space for solar power generation; second, Japanese manufacturers of solar power batteries could benefit from Japan's investment in solar power; and, finally investing in solar power by households and firms has been appealing to the investors with possibly good returns to be generated. At this time, however, many of the solar panels used in Japan are imported from abroad. ${ }^{5}$ As far as investment goes, both households and firms have found government subsidies and pricing policies with respect to solar power attractive. ${ }^{6}$ These conditions that favor solar power are not satisfied by other renewable energy sources. For example, noise pollution of wind power, the strong opposition from the local hot spa operators against geothermal power, and other reasons have prevented more large-scale investments in these sources. ${ }^{7}$ This is probably unfortunate

\footnotetext{
${ }^{4}$ Hydro power here does not include large-scale dam based hydro generation ${ }^{5}$ The total supply of solar power panels was $8,545,732 \mathrm{~kW}$ in fiscal year 2013 in which $4,814,303 \mathrm{~kW}$ or $56.3 \%$ were imported, according to Japan Photovoltaic Energy Association [2].

${ }^{6}$ Appendix $\mathrm{C}$ shows the pricing of Feed-in-Tariffs (FITs) currently in use in Japan. Investment subsidies seemed to have had only limited effects in general, and Japanese government subsidies in particular were eliminated in 2012.

${ }^{7}$ Large scale solar panels also cause certain problems to the localities. For example, glare reflecting the sun on the road, heat reflections in the neighborhoods of solar panels, and land speculation for solar panel investment have been often reported. Solar panels on house roofs, on the other hand, do not seem to cause such problems. Also Japanese FITs pricing favors smal scale generation of solar and wind power (see Appendix $\mathrm{C}$ ). Another reason that has prevented rapid development of geothermal power is that since many geothermal resources are located in national parks, the development of geothermal power requires strict environmental assessment and takes time.
} 
Table 1: Descriptive Statistics for our Basic Variables Used in our Regressions (Models 1 - 8)

\begin{tabular}{|c|c|c|c|c|c|c|c|}
\hline Variable & Mean & Std. Dev. & Median & Minimum & Maximum & $\begin{array}{l}\text { \# of } \\
\text { zeros }\end{array}$ & $\begin{array}{l}\text { \# of } \\
\text { obs. }\end{array}$ \\
\hline Per capita Income (thousand yen, per year) & 2826.6 & 396.8 & 2816.0 & 2102.0 & 4508.0 & 0 & 47 \\
\hline $\begin{array}{l}\text { Employment earnings per employed person (thousand } \\
\text { yen, per year) }\end{array}$ & 4264.2 & 509.4 & 4305.0 & 3244.0 & 6309.0 & 0 & 47 \\
\hline Workers (number of workers including self-employed) & 1292536.7 & 1439293.7 & 779891.0 & 285660.0 & 8380171.0 & 0 & 47 \\
\hline Employed (number of employed persons) & 1134661.1 & 1153513.9 & 659412.0 & 242671.0 & 5495525.0 & 0 & 47 \\
\hline Population density (persons/km2) & 672.5 & 1204.8 & 277.0 & 65.1 & 6314.6 & 0 & 47 \\
\hline Biofuel $(\mathrm{kW}) * * *$ & 1758.6 & 3040.5 & 100.0 & 0.0 & 14010.0 & 21 & 47 \\
\hline Geothermal (kW) & 4.0 & 21.5 & 0.0 & 0.0 & 139.6 & 45 & 47 \\
\hline Hydro $(\mathrm{kW})$ & 170.1 & 313.4 & 3.0 & 0.0 & 1600.0 & 21 & 47 \\
\hline Wind $(k W)$ & 2248.9 & 6673.2 & 0.0 & 0.0 & 28800.0 & 36 & 47 \\
\hline PVSUN (=PV $x$ hours of sun in kWh) * & 416442.2 & 286475.9 & 322303.8 & 39717.4 & 1099664.5 & 0 & 47 \\
\hline PV (solar power, kW) & 203595.5 & 132527.7 & 170599.2 & 24115.0 & 542118.8 & 0 & 47 \\
\hline Tokyo dummy** & 0.0213 & 0.1459 & 0 & 0 & 1 & 46 & 47 \\
\hline
\end{tabular}

Notes:

${ }^{*}$ PVSUN is PV (solar power) capacity multiplied by hours of sunshine.

**Tokyo is exceptional among included regions in many ways (e.g. very high income).

${ }^{* * * B}$ Biofuel is the sum of the capacity of all biomass power generation multiplied by fuels biomass ratio.

Sources: [3], [4], [5], [6].

particularly for geothermal development given that Japan's resource potential in this area is substantial. ${ }^{8}$

In our basic regression equations these variables given in Table $\mathbf{1}$ are used as dependent and explanatory variables. ${ }^{9} 10$

\section{ESTIMATING COMMUNITY-SPECIFIC ECONOMIC IMPACTS OF RENEWABLE ENERGY INVESTMENT ON PER CAPITA INCOME AND EMPLOYMENT INCOME VARIABLES}

We estimate the economic impacts of (cumulative) investment in renewable energy generation on per

\footnotetext{
${ }^{8}$ Wind power operates when wind speed is between 4 and $25 \mathrm{~m} / \mathrm{s}$. There are numerical data on wind at the $500 \mathrm{~m}$ mesh at the heights of $30 \mathrm{~m}, 50 \mathrm{~m}$ and $70 \mathrm{~m}$, but these data are too detailed to be linked with data for economic activities. We would like to explore these issues in our future research.

${ }^{9}$ We should note that most of solar power generation capacity was built prior to the sorts of economic impacts we try to measure here emerge. In this sense our investment capacity variables are regarded as econometrically predetermined variable. Using predetermined variables here may not necessarily eliminate endogeneity (simultaneous) bias because of the possible presence of public expectations for growth in solar power generation. Such expectations may drive both our capacity variables and unobservable factors buried in the error terms that determine our dependent variables. Another source of endogeneity bias may arise from the zero lower bounds for our explanatory variables. Such zeros may induce correlations between the equation error term and the explanatory variables. Fortunately there are no zeros in our PV capacity $x$ hours (PVSUN) variable, and hence no endogeneity bias from the zero bounds is likely to be present in our specifications. We present more discussions on this later in the paper.

${ }^{10}$ In addition to these basic variables we have experimented with some additional variables related to renewable energy generation, most of which turned out to be statistically insignificant. We plan to analyze these dropped variables further in our future study.
}

capita national income and also employment income per employed person variables. We chose these two dependent variables to study regional economic impacts in terms of broader investment effects (national income) and more employment income specific impacts of investment (employment income). In other words, employment income variable measures the amounts of income a person in the community receives from employment, while per capita national income measures broader impacts of the investment including direct economic benefits (e.g. investment-related purchases of material supply and services and employment income) and indirect benefits (e.g. employment income-generated consumption). ${ }^{11}$

Table 2 shows our regression results with the two income variables (national income and employment income) as dependent variables. ${ }^{12}$ Each regression was run in two specifications (models 1 versus 3 , and models 2 versus 4 ). Our results are robust and PVSUN is consistently significant with positive coefficients. On the other hand Biofuel was marginally significant at best and Geothermal is statistically significant and

\footnotetext{
${ }^{11}$ For example, supply chain effects (equivalently the input-output relations) are likely to allow self-employed persons to receive economic benefits generated by the induced effects of the investment.

${ }^{12}$ As noted earlier, many regressions were run with many added explanatory variables but we show here only those specifications with statistically significant explanatory variables. This applies also to our regression results presented in the next section.
} 
Table 2:

\begin{tabular}{|c|c|c|c|c|}
\hline Model 1 & \multicolumn{3}{|c|}{ per capita national income in 1000 yen } & p-value \\
\hline Constant & 2594.5 & 99.39 & 26.104 & $2.20 \mathrm{E}-16^{* * *}$ \\
\hline Geo & -3.0276 & 0.45075 & -6.7168 & $3.70 \mathrm{E}-08^{\star \star *}$ \\
\hline Bio & 0.00013 & 0.013246 & 0.0099 & 0.992181 \\
\hline PVSUN & 0.00049 & 0.000167 & 2.9741 & $0.004852^{* * *}$ \\
\hline Residual s.e. & 281.2 & $d f=$ & 42 & \\
\hline R-squared & 0.5415 & adj.R2 & 0.4978 & \\
\hline F-statistic & 12.4 & $d f=$ & $(4,42)$ & \\
\hline BP & 3.7479 & $p$-value & 0.4412 & \\
\hline
\end{tabular}

\begin{tabular}{|c|c|c|c|c|}
\hline \multirow{2}{*}{ Model 2} & \multicolumn{3}{|c|}{ per capita employment income in 1000 yen } & \multirow{2}{*}{ p-value } \\
\hline & coeff. & s.e. & t-value & \\
\hline Constant & 3874.1 & 95.818 & 40.4316 & $2.20 \mathrm{E}-16^{* * *}$ \\
\hline Geo & -4.0744 & 0.56934 & -7.1564 & $8.69 \mathrm{E}-09^{* * *}$ \\
\hline Bio & 0.051138 & 0.013716 & 3.7285 & $0.000571^{* * *}$ \\
\hline PVSUN & 0.000658 & 0.000125 & 5.2426 & 4.83E- $-06^{* * *}$ \\
\hline Dummy Tokyo & 2010 & 71.796 & 27.996 & $2.20 \mathrm{E}-16^{* * *}$ \\
\hline Residual s.e. & 337.1 & $d f=$ & 42 & \\
\hline R-squared & 0.6001 & adj. R2 & 0.5621 & \\
\hline F-statistic & 15.76 & $d f=$ & $(4,42)$ & \\
\hline BP & 2.4806 & $p$-value & 0.6481 & \\
\hline HMC & 0.3089 & $p$-value & 0.028 & \\
\hline RESET & 0.59734 & $p$-value & 0.5551 & \\
\hline Rainbow & 1.4665 & p-value & 0.2042 & \\
\hline
\end{tabular}

\begin{tabular}{|c|c|c|c|c|}
\hline Model 3 & \multicolumn{3}{|c|}{ per capita national income in 1000 yen } & p-value \\
\hline Constant & 2614.3 & 100.45 & 26.027 & $2.20 \mathrm{E}-16^{\star * *}$ \\
\hline Geo & -3.2405 & 0.4598 & -7.0478 & $1.41 \mathrm{E}-08^{* * *}$ \\
\hline Bio & 0.00027 & 0.013639 & 0.0202 & 0.983973 \\
\hline Wind & -0.00966 & 0.004131 & -2.3388 & $0.024299^{* *}$ \\
\hline Dummy Tokyo & 1757.2 & 52.725 & 33.327 & $2.20 \mathrm{E}-16^{* * *}$ \\
\hline Residual s.e. & 276.3 & $d f=$ & 41 & \\
\hline R-squared & 0.5677 & $\operatorname{adj} . R^{2}$ & 0.5150 & \\
\hline F-statistic: & 10.77 & $d f=$ & $(5,41)$ & \\
\hline Rainbow & 1.2859 & p-value & 0.3003 & \\
\hline
\end{tabular}


(Table 2). Continued.

\begin{tabular}{|c|c|c|c|c|}
\hline \multirow{2}{*}{ Model 4} & \multicolumn{3}{|c|}{ per capita employment income in 1000 yen } & \multirow{2}{*}{$p$-value } \\
\hline & coeff. & s.e. & t-value & \\
\hline Constant & 3891.5 & 98.251 & 39.607 & $1.21 \mathrm{E}-08^{* * *}$ \\
\hline Geo & -4.2612 & 0.60059 & -7.095 & $1.21 \mathrm{E}-08^{* * *}$ \\
\hline Bio & 0.05126 & 0.013212 & 3.8801 & $0.000371^{\text {***}}$ \\
\hline Wind & -0.00848 & 0.005816 & -1.4573 & 0.152659 \\
\hline Dummy Tokyo & 1990.3 & 79.342 & 25.084 & $2.20 \mathrm{E}-16^{* \star *}$ \\
\hline Residual s.e. & 335.9 & $\mathrm{df}=$ & 41 & \\
\hline R-squared & 0.6124 & $\operatorname{adj} . R^{2}$ & 0.5651 & \\
\hline F-statistic: & 12.95 & $\mathrm{df}=$ & $(5,41)$ & \\
\hline Rainbow & 1.4638 & $p$-value & 0.2111 & \\
\hline
\end{tabular}

Notes: (i) ${ }^{* * *},{ }^{* *}$ and ${ }^{*}$ denote, respectively, significance levels at $1 \%, 5 \%$ and $10 \%$; (ii) also, standard errors (s.e.) reported here are heteroscedasticity-corrected standard errors; (iii) specification tests reported here are Breusch-Pagan (BP) test and Harrison-McCabe (HMC) test, both of which are rejected if heteroscedasticity is detected, Reset test for functional form (RESET), which is rejected if some additional variables are required for the regression model being estimated, and Rainbow test (Rainbow)for linearity, which is rejected if non-linearity in the regression model being estimated is found.

negative. Since these two variables are zero for many observations in the sample, it is safe to ignore these variables in these regressions (Table 1). In particular, there are only two observations for which Geothermal variable is positive in our sample. This suggests that no meaningful geothermal power generation related investment projects are taking place in Japan despite many apparent opportunities. ${ }^{13}$

\section{ESTIMATING COMMUNITY-SPECIFIC ECONOMIC IMPACTS OF RENEWABLE ENERGY INVESTMENT ON EMPLOYMENT OPPORTUNITIES}

Securing employment by investment is one of the most important policy objectives of all levels of government. Because many community decision makers including regional governments, firms and households are involved in investment decisions for regional renewable energy projects, we expect these projects have good possibilities to succeed and are expected to generate new employment in the region.

From Table 3 we see that PVSUN is positive and statistically consistent in all of our models of employment regressions. On the other hand, Bio is positive consistently but is not very significant. Geo is negative but statistically significant. Regression results

\footnotetext{
${ }^{13}$ Alternatively, there might be measurement problems of Geothermal variable in our data sources.
}

are similar for both employment variables (models 5 and 7 versus models 6 and 8 ). This suggests that both employed workers and self-employed and other workers who are not directly employed by firms do get benefit from the investment in solar power in their regions.

\section{Elasticity with Respect to Investing in Solar Power}

We have noted above that only solar power variable (PVSUN) which measures regional solar power capacity after adjusting for the actual hours of sunshine can give us policy implications with some realistic level of confidence (Tables 2 and 3 ). We have applied bootstrapping methods to estimate a $95 \%$ confidence interval of elasticity estimates for each of our models in Tables 2 and 3 . These are shown in columns 2 and 3 of Table 4.

The bootstrapped distributions of elasticities estimated in Table 4 (columns 3 and 4) have approximately normal shapes. ${ }^{14}$ These estimates suggest that a $1 \%$ increase in the PVSUN kW hours will result in $0.07 \%$ and $0.06 \%$ increases, respectively, in per capita income and per capita employment

\footnotetext{
${ }^{14}$ Mean elasticity estimates and their confidence intervals for our linear regression models are presented in Table 4 (column 3). The distributions of elasticity estimates for linear and log-log-models are available on request from the authors.
} 
Table 3:

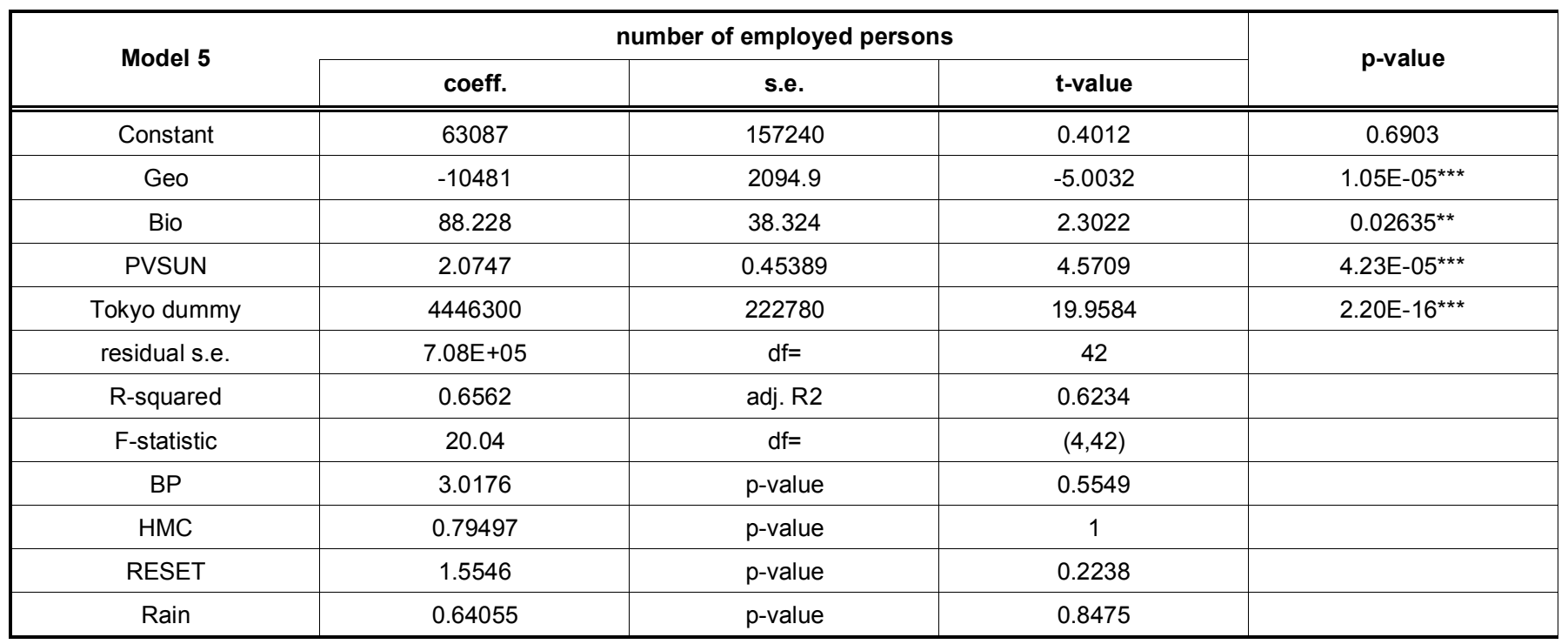

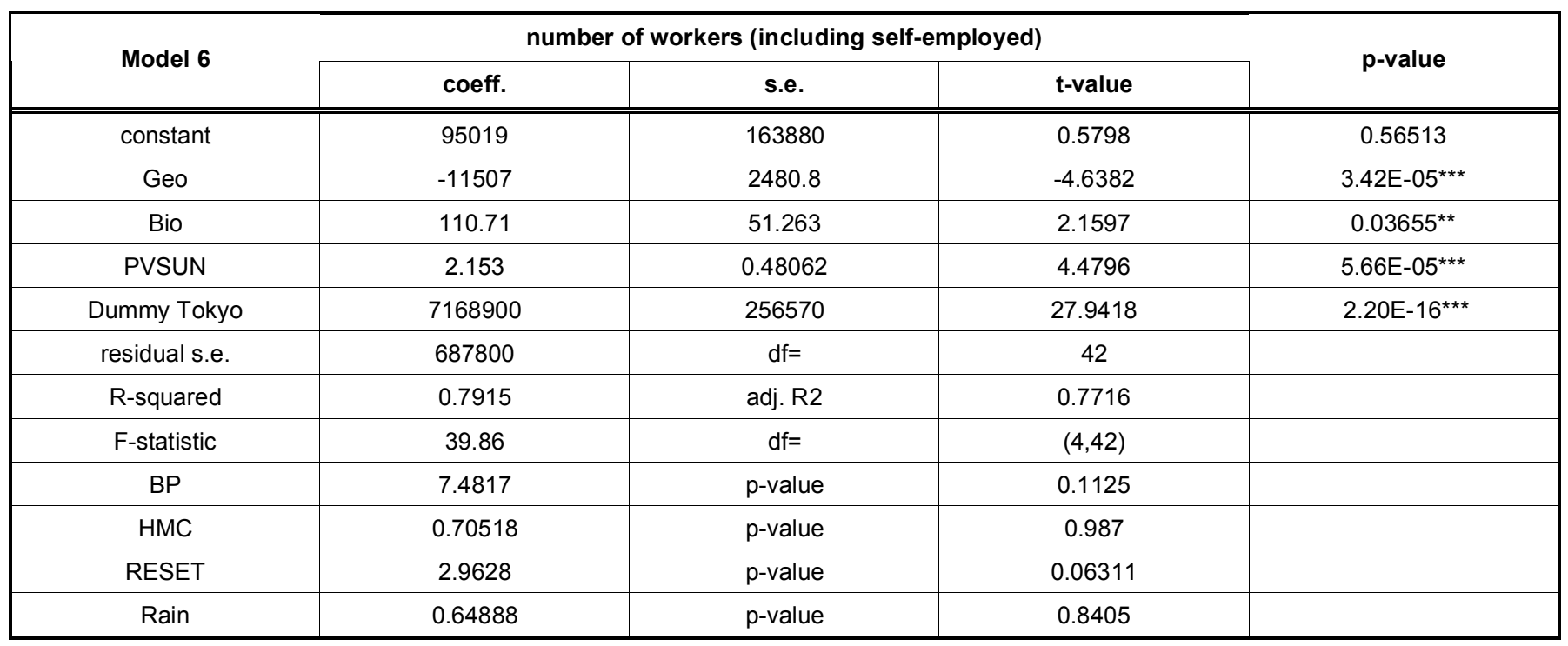

\begin{tabular}{|c|c|c|c|c|}
\hline \multirow{2}{*}{ Model 7} & \multicolumn{3}{|c|}{ number of employed persons } & \multirow{2}{*}{ p-value } \\
\hline & coeff. & s.e. & t-value & \\
\hline Constant & 47370 & 167510 & 0.2828 & 0.77876 \\
\hline Bio & 88.114 & 38.575 & 2.2842 & $0.02761^{* *}$ \\
\hline Wind & 7.6449 & 12.044 & 0.6347 & 0.52912 \\
\hline Dummy Tokyo & 4464100 & 233110 & 19.1501 & $2.20 \mathrm{E}-16^{* * *}$ \\
\hline residual s.e. & 714400 & $d f=$ & 41 & \\
\hline R-squared & 0.6581 & adj. R2 & 0.6164 & \\
\hline F-statistic & 15.79 & $d f=$ & $(5,41)$ & \\
\hline Rain & 0.62583 & p-value & 0.8571 & \\
\hline
\end{tabular}


(Table 3). Continued.

\begin{tabular}{|c|c|c|c|c|}
\hline Model 8 & \multicolumn{3}{|c|}{ number of workers (including self-employed) } & p-value \\
\hline Constant & 75340 & 171320 & 0.4398 & 0.662415 \\
\hline Geo & -11296 & 2579.7 & -4.3787 & 8.06E-05*** \\
\hline Bio & 110.57 & 52.008 & 2.126 & $0.039571^{* *}$ \\
\hline Dummy Tokyo & 7191200 & 267220 & 26.9114 & $<2.20 \mathrm{E}-16^{* * *}$ \\
\hline residual s.e. & 692900 & $d f=$ & 41 & \\
\hline R-squared & 0.7935 & Adjusted R2 & 0.7683 & \\
\hline F-statistic & 31.5 & $d f=$ & $(5,41)$ & \\
\hline RESET & 2.1431 & p-value & 0.1309 & \\
\hline Rain & 0.69372 & p-value & 0.7989 & \\
\hline
\end{tabular}

Notes: (i) ${ }^{* * *},{ }^{* *}$ and ${ }^{*}$ denote, respectively, significance levels at $1 \%, 5 \%$ and $10 \%$; (ii) also, standard errors (s.e.) reported here are heteroscedasticity-corrected standard errors; (iii) specification tests reported here are Breusch-Pagan (BP) test and Harrison-McCabe (HMC) test, both of which are rejected if heteroscedasticity is detected, Reset test for functional form (RESET), which is rejected if some additional variables are required for the regression model being estimated, and Rainbow test (Rainbow) for linearity, which is rejected if non-linearity in the regression model being estimated is found.

Table 4: Elasticity Estimates with Respect to PVSUN

\begin{tabular}{|c|c|c|c|}
\hline & dependent variable & $\begin{array}{l}\text { 95\% confidence interval } \\
\text { (mean elasticity) }\end{array}$ & Elasticity estimated by log-log model \\
\hline model 1 & per capita income & $0.0294,0.1194(.0744)$ & $0.0273(0.0183)^{*}$ \\
\hline model 2 & per capita emp. income & $0.0411,0.0917(.0664)$ & $0.0552(0.0125)^{*}$ \\
\hline model 4 & per capita emp. income & $0.0406,0.0889(.0647)$ & $0.0718(0.0166)$ \\
\hline model 6 & no. of workers & $0.5246,1.180(.8523)$ & $0.6727(0.1470)$ \\
\hline model 8 & no. of workers & $0.4979,1.158(.8279)$ & $0.4318(0.1169)^{*}$ \\
\hline
\end{tabular}

income. Similarly, a $1 \%$ increase in the PVSUN kW hours will result in $0.7 \%$ and $0.8 \%$ increases, respectively, in the numbers of employed workers and all workers.

\section{Comparison with Elasticity Estimates by Log-Log Regression}

Instead of using linear regression models for estimating our models $1-8$, log-log regression models could be used particularly for estimating elasticities of our interest more directly. This was done in our exploratory regression. Column 4 of Table 4 shows our elasticity estimates with heteroscedasticity-corrected standard errors in parentheses. Unfortunately these models are not fully compatible with our linear models. ${ }^{15}$ Nevertheless, elasticity estimates are not far apart between these two types of models. ${ }^{16}$

\section{CONCLUDING REMARKS}

In this exploratory study we have shown that investing in renewable energy projects, particularly solar power projects can have positive impacts on

\footnotetext{
${ }^{15}$ The sample sizes for our log-log models are: 25 for models $3,4,5$ and 6 , and 10 for models 1, 2, 7 and 8 . The log-log model results with * in column 4 are not compatible with results from the corresponding linear models given in columns 2 and 3 . This is because log-log models include wind power (Wind) and solar power (PVSUN) but do not include Biofuel due to missing variables. ${ }^{16}$ But clearly there are some types of specification errors in linear and particularly in log-log models. One possible reason is the small sample size for log-log models due to missing observations for some states. This and other specification issues need to be further investigated.
} 
regional income and employment. Solar energy and other types of renewable energy generation requires investing in the localities where certain physical conditions for specific power generation are satisfied. Yet for such investments to be meaningful from the national objectives of power generation and environmental sustainability, they need to take place and distributed widely over the nation's regions. Our results show, at least tentatively, that solar power generation in many localities in Japan can benefit the local regions as long as such investments are feasible. For policy purposes it would be of interest to be able to estimate elasticities of income and employment with respect to investment in renewable energy.

In this paper we have presented a basic empirical framework in which to estimate the economic impacts at the regional level of investing in the capacity to generate solar power and other renewable energy. In this study we have shown that these economic impacts on regional income and employment are positive. We have also identified certain conditions that need to be addressed in further research along the lines we proposed here. These include developing a methodology to cope with many observations in the sample for which some renewable energy capacity is zero (missing variable problem). Since these zeros are likely to be a result of the regions' decisions about investing in the capacity of certain renewable energy, they may be correlated with the error term of the regression equation to estimate. This implies that we may need to estimate our equations while correcting for the endogeneity problem. The presence of many zeros also makes it difficult to estimate regression equations using a double log (i.e. log-log) form which would be suitable for estimating elasticities. Finally, while we have estimated our equations using cross-sectional data for a single year, we also need to incorporate multiple years of observations once such data becomes available.

Because of the limitations of our data on Japanese prefectures, our sample is of cross-sectional nature. For this reason our results are not readily comparable with those in related studies in the literature. For example, Heinbach et al. [7], Prahl [8] and RaupachSumiya [9] present results on the relationships between the use of renewable energy and regional communities in Germany. Because of the differences in the nature of the data bases and methodologies used in these studies, we cannot present immediate comparisons between their results and ours. For such comparisons, it might be useful to combine available Input-Output tables for Japan with our data in our future studies. ${ }^{17}$

\section{ACKNOWLEDGEMENT}

The authors thank an anonymous referee of this journal for many helpful comments on our earlier version of the paper. M. Nakamura's research was in part funded by a grant from the Social Sciences and Humanities Research Council of Canada.

\section{APPENDIX A. DATA SOURCES AND INSTITUTIONAL SETTINGS}

The Agency for Natural Resources and Energy of Japan has started a Feed in Tariff System on renewable resources since July 2012 . Tariff rates have been revised (see Table 6 in Appendix C). The capacity of renewable energy sources we consider here are accumulated amounts from July 2012 to March 2014.

\section{Data Sources}

The most recent data on the system of prefectural accounts that is available are for the 2013 Fiscal Year. Therefore we use data for the 2013 Fiscal Year (April 2013 to March 2014). Specifically, our main variables of interest are as follows:

Per capita income (in 1000 yen, yearly) [11]

Employment income per employed person (in 1000yen, yearly) [11]

The number of employed persons [11]

The number of workers [11]

Hours of sunshine [12]

Area of prefecture [5]

Capacity of renewable resources [3]

In addition to Table 1 in which descriptive statistics for our basic variables are presented, we present Table 5 in Appendix B below in which we show some additional variables related to renewable energy generation.

We hope to incorporate more detailed information presented in this Table in our future study.

\footnotetext{
${ }^{17}$ We also note that Nakano, Arai and Washizu [10] use Japanese Input-Output tables to analyze renewable energy.
} 
APPENDIX B.

Table 5: Descriptive Statistics for other Variables of Interest Related to Renewable Energy Generation

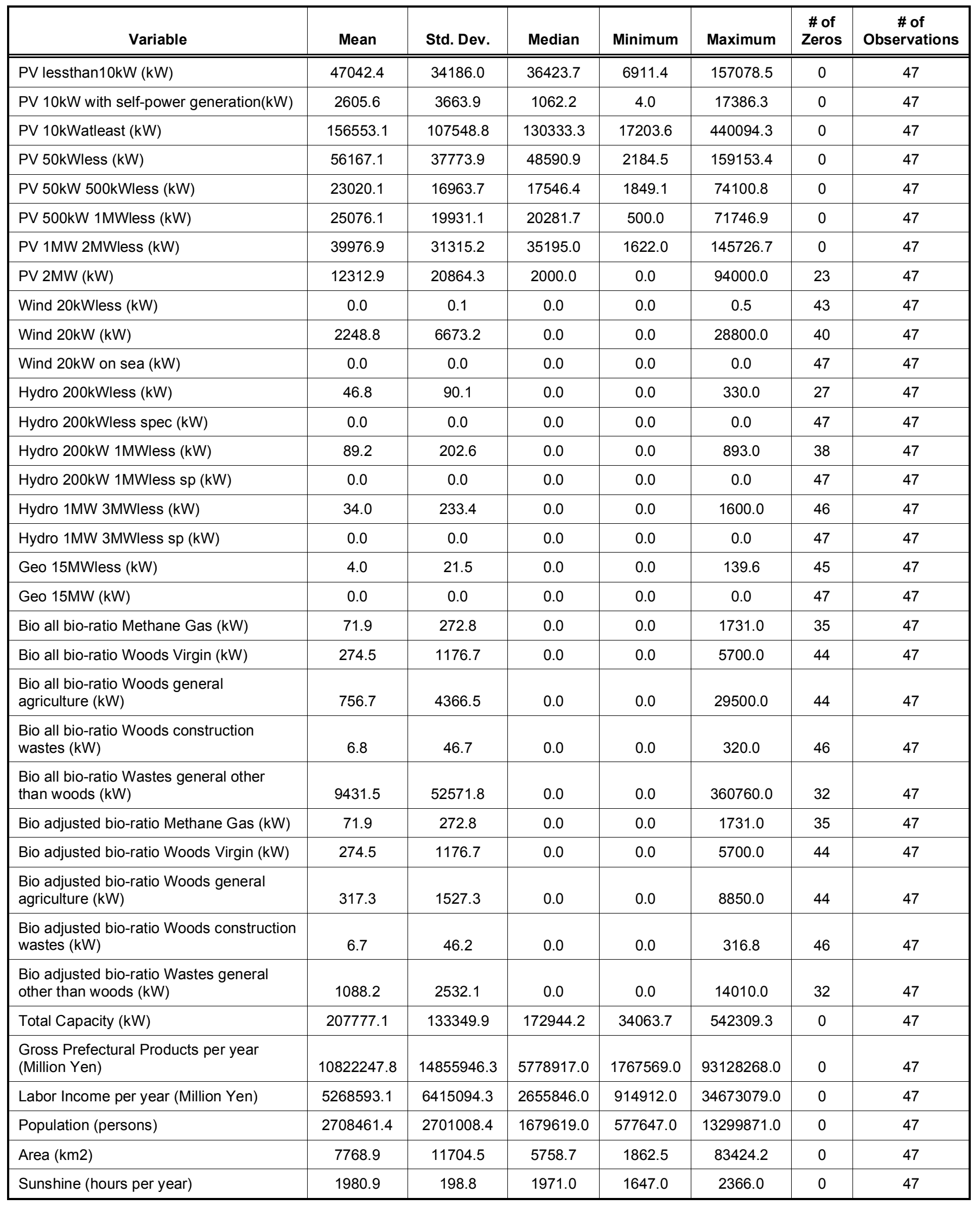




\section{APPENDIX C. FEED IN TARIFF SYSTEM IN JAPAN}

Table 6: Revision of the Feed in Tariff System

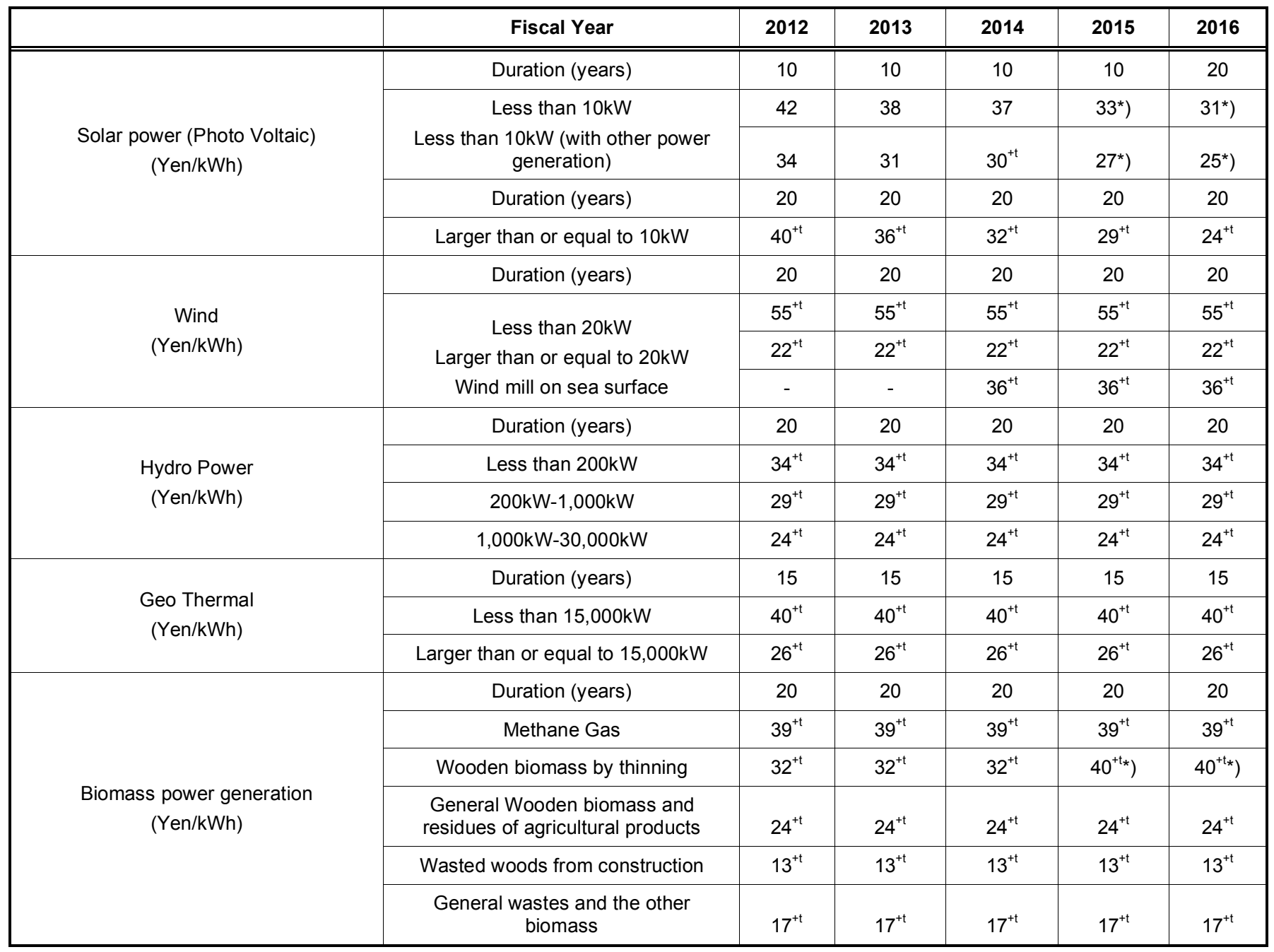

Notes: *) There are some minor differences in published figures at source.

$+\mathrm{t})$ means appropriate consumption taxes are added: 5\% (2012-2013) and 8\% (2014- ).

Source: [14].

The tariff (purchasing price) is determined by the capacity and duration of investment as well as the year of investment. For example, solar power generation produces 42 yen every kWh for 10 years (from 20122022). At that time, typical electricity prices for households are $18.89 \mathrm{yen} / \mathrm{kWh}$ up to $120 \mathrm{kWh}$ per month, 25.19 yen/kWh from 120kWh-300kWh per month, and 29.4 yen/kWh from $300 \mathrm{kWh}$ per month (Contract types B and C, Tokyo Electricity Power Co.). Most households with solar panels can sell solar generated power at 42 yen per kWh and buy electricity for 18.89 yen to 29.4 yen per kWh. The price of electricity was liberated in April 2016. Households can now buy electricity at a little lower price per kWh than before, but the difference is marginal.

\section{REFERENCES}

[1] Ministry of Economy, Trade and Industry 2016, Report on sustainable biomass power generation (in Japanese), Mitsubishi UFJ Research and Consulting [report on the Internet]: Available from: www.meti.go.jp/meti lib/report/ 2016fy/000971.pdf

[2] Japan Photovoltaic Energy Association, 2016 [homepage on the Internet, updated on 2016 November 22]: Available from: http://www.jpea.gr.jp.

[3] Agency for Natural Resources and Energy, the Government of Japan, 2016 [statistical data on the Internet, updated on 2016 December 6]: Available from: http://www.fit.go.jp/ statistics/public sp.html.

[4] Cabinet Office, Government of Japan, 2016 [statistical data on the Internet, updated on 2016 July 22]: Available from: http://www.esri.cao.go.jp/jp/sna/menu.html

[5] Geospatial Information Authority of Japan, Ministry of Land, Infrastructure, Transportation and Tourism, the Government 
of Japan, 2016 [statistical data on the Internet, updated on 2016 May 31]: Available from: http://www.gsi.go.jp/ KOKUJYOHO/MENCHO-title.html or http://www.gsi.go.jp/ ENGLISH/index.html.

[6] Japan Meteorological Agency, 2016 [statistical data on the Internet, updated on 2017 January 14]: Available from: http://www.jma.go.jp/jma/menu/menureport.html

[7] Heinbach K, Aretz A, Hirsch B, Prahl A, SAlecki S. Renewable energies and their impact on local value added and employment. Energy Sustainability and Society 2014; 4: 1.

https://doi.org/10.1186/2192-0567-4-1

[8] Prahl A. Renewable energies' impact on value added and employment in Germany. A paper presented at the Community Power Conference, Fukushima, Japan; February 2014.

[9] Raupach-Sumiya J. Measuring regional economic valueadded of renewable energy: The case of Germany. Shakai System Kenkyu 2014; 29: 1-31.
[10] Nakano S, Arai S, Washizu A. Economic impacts of Japan's renewable energy sector and the feed-in tariff system: using an input-output table to analyze a next-generation energy system. Environ Econ Policy Stud 2016.

https://doi.org/10.1007/s10018-016-0158-1

[11] Cabinet Office, the Government of Japan, Annual Report on Prefectural Accounts, 2013 Fiscal Year: [statistical data on the Internet]: Available from: http://www.esri.cao.go.jp/ index.html (in Japanese only)

[12] Japan Meteorological Agency, Historical Weather Data, 2016 [statistical data on the Internet, updated on 2017 January 14]: Available from: http://www.data.jma.go.jp/gmd/risk/obsdl/ (in Japanese only).

[13] Agency for Natural Resources and Energy, the Government of Japan [statistical data on the Internet, updated on 2016 December 16]: Available from: http://www.fit.go.jp/statistics/ public_sp.html.

[14] Agency for Natural Resources and Energy [updated March 2016]: Available from: http://www.enecho.meti.go.jp/ category/saving_and_new/saiene/data/kaitori/2016_fit.pdf 